\title{
Sensitive electrochemical immunosensor based on three-dimensional nanostructure gold electrode
}

\author{
This article was published in the following Dove Press journal: \\ International Journal of Nanomedicine \\ 19 March 2015 \\ Number of times this article has been viewed
}

\author{
Guangxian Zhong ${ }^{1,2, *}$ \\ Ruilong Lan ${ }^{3, *}$ \\ Wenxin Zhang ${ }^{1,4}$ \\ Feihuan $\mathrm{Fu}^{5}$ \\ Yiming Sun ${ }^{1,4}$ \\ Huaping Peng ${ }^{1,4}$ \\ Tianbin Chen ${ }^{3}$ \\ Yishan $\mathrm{Cai}^{6}$ \\ Ailin Liu ${ }^{1,4}$ \\ Jianhua $\operatorname{Lin}^{2}$ \\ Xinhua $\operatorname{Lin}^{1,4}$ \\ 'Department of Pharmaceutical \\ Analysis, Faculty of Pharmacy, Fujian \\ Medical University, ${ }^{2}$ Department \\ of Orthopaedics, ${ }^{3}$ The Centralab, \\ First Affiliated Hospital of Fujian \\ Medical University, ${ }^{4}$ Nano Medical \\ Technology Research Institute, \\ Fujian Medical University, Fuzhou, \\ ${ }^{5}$ Department of Endocrinology, The \\ County Hospital of Anxi, Anxi, ${ }^{6}$ Fujian \\ International Travel Healthcare \\ Center, Fujian Entry-Exit Inspection \\ and Quarantine Bureau, Fuzhou, \\ People's Republic of China \\ *These authors contributed equally \\ to this work
}

Correspondence: Ailin Liu

Department of Pharmaceutical Analysis,

Faculty of Pharmacy, Fujian Medical

University, Fuzhou 350004, People's

Republic of China

Email ailinliu@fjmu.edu.cn

Jianhua Lin

Department of Orthopaedics, First

Affiliated Hospital of Fujian Medical

University, Fuzhou 350004, People's

Republic of China

Email jianhual@।26.com

\begin{abstract}
A sensitive electrochemical immunosensor was developed for detection of alpha-fetoprotein (AFP) based on a three-dimensional nanostructure gold electrode using a facile, rapid, "green" square-wave oxidation-reduction cycle technique. The resulting threedimensional gold nanocomposites were characterized by scanning electron microscopy and cyclic voltammetry. A "sandwich-type" detection strategy using an electrochemical immunosensor was employed. Under optimal conditions, a good linear relationship between the current response signal and the AFP concentrations was observed in the range of $10-50 \mathrm{ng} / \mathrm{mL}$ with a detection limit of $3 \mathrm{pg} / \mathrm{mL}$. This new immunosensor showed a fast amperometric response and high sensitivity and selectivity. It was successfully used to determine AFP in a human serum sample with a relative standard deviation of $<5 \%(n=5)$. The proposed immunosensor represents a significant step toward practical application in clinical diagnosis and monitoring of prognosis.
\end{abstract}

Keywords: electrochemical immunosensors, three-dimensional nanostructure gold electrode, square-wave oxidation-reduction cycle, alpha-fetoprotein

\section{Introduction}

Immunoassays based on specific recognition between an antigen and an antibody have been used successfully in a number of fields, including medical detection, processing quality control, and environmental monitoring. ${ }^{1-3}$ Traditional immunoassay methods have included the radioimmunoassay, enzyme-linked immunosorbent assay, and electrochemiluminescence immunoassay. In spite of their good sensitivity, the radioimmunoassay significantly increases the radioactivity hazard for laboratory workers and the enzyme-linked immunosorbent assay is tedious and time-consuming. Newer methods, including surface plasmon resonance, ${ }^{4}$ quartz crystal microbalance, ${ }^{5}$ and optical $^{6}$ and electrochemical methods, ${ }^{7}$ have attracted considerable interest for immunoassays due to their rapid recognition and simple fabrication. Among these methods, the electrochemical immunoassay has received much attention in view of its high sensitivity and low cost. ${ }^{7,8}$

The crucial step in construction of an electrochemical immunosensor is efficient immobilization of biomolecules onto the electrode surface. ${ }^{9}$ New opportunities for fabrication of highly sensitive electrochemical immunosensors have been opened up by the advent of nanomaterials and nanotechnologies. ${ }^{10}$ Advances in biomolecular detection have included use of nanomaterials, such as nanotubes, nanoparticles, and nanowires, as a medium of signal amplification. ${ }^{11-13}$ In recent years, due to its interesting properties, including a large surface area, superior conductivity, biocompatibility, and high stability, nanoporous gold has attracted considerable attention. Several methods, including electrochemical deposition, ${ }^{14}$ electrochemical erosion, ${ }^{15}$ "direct freezing", ${ }^{16}$ a voltage-induced dimension change method, ${ }^{17}$ a "dealloying process", ${ }^{18-20}$ 
template synthesis, ${ }^{21,22}$ and repetitive square-wave oxidationreduction cycle $(\mathrm{SWORC})^{23}$ were been used to prepare a three-dimensional gold (3D-Au) nanostructure. Due to the time-saving, easy, and controllable preparation of nanoporous gold, SWORC is very attractive among these methods. ${ }^{24,25}$

Alpha-fetoprotein (AFP) is normally synthesized by the liver, yolk sac, and gastrointestinal tract in the human fetus. Plasma levels of AFP decrease rapidly after birth and reach normal adult levels by the age of 8-12 months. Elevated serum AFP levels in adults are significant in the diagnosis of ataxia-telangiectasia syndrome, hereditary tyrosinemia, cirrhosis, alcoholic hepatitis, hepatocellular carcinoma, and viral hepatitis, and are also useful for monitoring the effectiveness of surgical and chemotherapeutic management of hepatomas and germ cell neoplasms. ${ }^{8}$ AFP testing is currently performed using the radioimmunoassay and enzyme-linked immunosorbent assay. ${ }^{26,27}$ However, there are some limitations, such as radiation hazards and a long analysis time. Therefore, it is important to explore new routes for detection of AFP.

In the present study, a facile electrochemical immunosensor based on a 3D-Au electrode was developed for detection of AFP. The 3D-Au electrode was prepared by a simple, rapid, and "green" SWORC approach. The 3D-Au electrode was then used as a substrate for construction of a "sandwichtype" AFP immunosensor. This new immunosensor showed a fast amperometric response, high sensitivity, and selectivity, and was used to assay of AFP in a real serum sample with a satisfactory result. The proposed immunosensor represents a significant step towards practical application in clinical diagnosis and prognostication.

\section{Materials and methods Chemicals and materials}

3-mercaptopropionic acid, nitric acid, sulfuric acid, potassium permanganate, ethanol, $N$-hydroxysuccinimide, and 1-ethyl-3-(3-dimethylamino propyl) carbodiimide hydrochloride (EDC) were provided by Sinopharm Chemical Reagent Co Ltd (Shanghai, People's Republic of China). Bovine serum albumin was sourced from Sigma-Aldrich (St Louis, MO, USA). 3,3',5,5'-tetramethylbenzidine (TMB) substrate (K-blue low activity substrate) was purchased from Neogen (Lansing, MI, USA). Human serum samples were obtained from the First Affiliated Hospital of Fujian Medical University. All chemicals were of analytical reagent grade and were used without further purification. All solutions were prepared with Milli Q water (18 $\mathrm{M} \Omega \cdot \mathrm{cm}$ resistivity) from a Millipore system (Billerica, MA, USA).
Mouse anti-AFP monoclonal antibody $(8.556 \mathrm{mg} / \mathrm{mL})$ and horseradish peroxidase (HRP)-conjugated mouse antiAFP monoclonal antibody $(13.34 \mathrm{mg} / \mathrm{mL})$, AFP standard solution, and cancer antigen 125, 153, and 199 standard solutions were from Zhengzhou Biocell Biotechnology Co Ltd (Zhengzhou, People's Republic of China). The antibody dilution was $10 \mathrm{mM}$ phosphate-buffered saline (PBS) containing $0.08 \mathrm{M} \mathrm{NaCl}$ ( $\mathrm{pH} 7.4)$. The antibodies were aliquoted and stored at $-20^{\circ} \mathrm{C}$. The purified antibodies were diluted upon use in PBS suitable for the immobilizing and capture reactions.

\section{Apparatus}

All electrochemical measurements were performed on a $\mathrm{CHI}$ $760 \mathrm{D}$ Electrochemical Workstation (CH Instruments, Austin, TX, USA). Electrochemical experiments were carried out with a conventional three-electrode system comprising a 3D-Au working electrode, an $\mathrm{Ag} / \mathrm{AgCl}$ (with saturated $\mathrm{KCl}$ ) reference electrode, and a platinum wire auxiliary electrode. Cyclic voltammetry was carried out at a scan rate of $100 \mathrm{mV}$ per second. Amperometric detection was performed at a fixed potential of $100 \mathrm{mV}$. Steady-state currents were recorded within 100 seconds. Scanning electron microscopic images were obtained using an S-4800 instrument (Hitachi, Tokyo, Japan). Atomic force microscopic images were acquired using an SPM-Multimode 8 system (Bruker, Santa Barbara, CA, USA) with Nanoscope Analysis version 1.40.0.0 software. All the images presented in this paper were acquired using ScanAsyst mode under ambient conditions.

\section{Preparation of 3D-Au electrode}

The method used to prepare the 3D-Au electrode was the same as that described in our previous reports. ${ }^{24,25}$ Briefly, before each experiment, a gold electrode ( $2 \mathrm{~mm}$ in diameter) was polished with 1.0, 0.3, and $0.05 \mu \mathrm{m}$ alumina powder. The gold electrode was then cleaned ultrasonically sequentially and thoroughly in ethanol and deionized water. The nanoporous gold electrode was electrochemically cleaned in fresh $0.5 \mathrm{M}$ $\mathrm{H}_{2} \mathrm{SO}_{4}$ solution by potential scanning between $-0.35 \mathrm{~V}$ and $1.5 \mathrm{~V}$ until a cyclic reproducible voltammogram was obtained to remove any possible impurities on the surface ${ }^{28}$ and the electrode was rinsed with doubly distilled water, then the electroabsorption charge of the $\mathrm{O}$ adatoms between the rough gold electrode and the flat gold electrode was checked.

\section{Fabrication of immunosensor}

The cleaned 3D-Au electrode was first immersed in an aqueous solution of $5 \mathrm{mM} 3$-mercaptopropionic acid for 24 hours at 


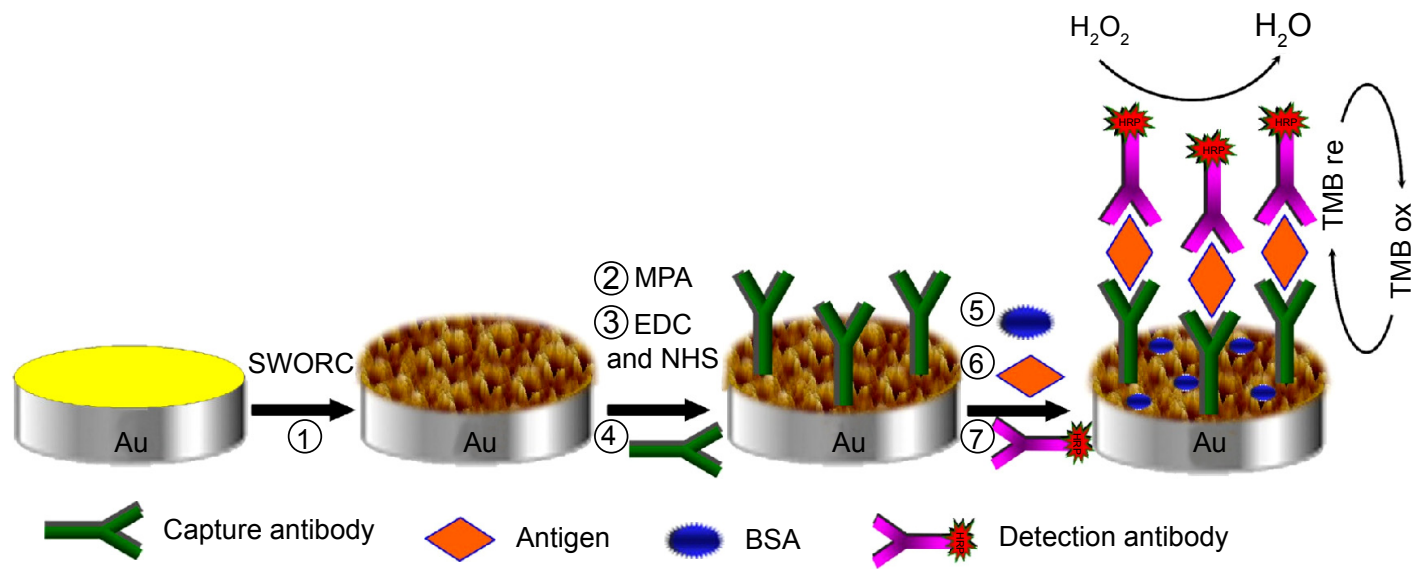

Figure I Schematic representation of the fabrication procedure for an immunosensor based on a 3D-Au electrode.

Abbreviations: 3D, three-dimensional; Au, gold; BSA, bovine serum albumin; EDC, I-ethyl-3-(3-dimethylamino propyl) carbodiimide hydrochloride; MPA, 3-mercaptopropionic acid; NHS, N-hydroxysuccinimide; SWORC, square-wave oxidation-reduction cycle; HRP, horseradish peroxidase.

room temperature. After thorough rinsing with deionized water to remove the physically adsorbed 3-mercaptopropionic acid, the nanoporous gold electrode was immersed in $10 \mathrm{mM}$ PBS (pH 7.4) with $20 \mathrm{mg} / \mathrm{mL}$ of EDC and $10 \mathrm{mg} / \mathrm{mL}$ of $N$-hydroxysuccinimide for 40 minutes. The activated 3D-Au electrode was thoroughly rinsed with $10 \mathrm{mM}$ PBS (pH 7.4). Next, $5 \mu \mathrm{L}$ of capture antibody (mouse monoclonal antibody directed against AFP, $0.5 \mathrm{mg} / \mathrm{mL}$ solution) was dropped onto the electrode surface and incubated overnight to yield sensing interfaces. A blocking treatment aimed at preventing nonspecific responses during incubation of the sample was carried out by casting $10 \mu \mathrm{L}$ of $5 \%(\mathrm{v} / \mathrm{w})$ bovine serum albumin at room temperature for 1 hour, followed by careful washing in $10 \mathrm{mM}$ PBS (pH 7.4). Thereafter, $5 \mu \mathrm{L}$ of AFP antigen solution at different concentrations were added onto the electrode surface and incubated for 1 hour, and the modified electrode was then rinsed extensively to remove unbound antigen molecules. Next, $5 \mu \mathrm{L}$ of detection antibody (HRP-conjugated mouse monoclonal antibody directed against AFP, $0.02 \mathrm{mg} / \mathrm{mL}$ ) was dropped onto the modified electrode surface and incubated for 1 hour, after which the electrode was washed and ready for measurement. A schematic illustration of the stepwise preparation of the immunosensor is shown in Figure 1.

\section{Electrochemical measurement}

Electrochemical measurements, including cyclic voltammetry and amperometric i-t curve studies, were performed using a commercial TMB substrate solution containing a certain percentage of $\mathrm{H}_{2} \mathrm{O}_{2}$. Cyclic voltammetry was carried out at a scan rate of $100 \mathrm{mV}$ per second. Amperometric detection was performed at $100 \mathrm{mV}$. Steady-state current was usually reached within 100 seconds. The data for the condition, optimization, and calibration curves was the average of three measurements.

\section{Results and discussion Preparation of 3D-Au electrode}

Figure $2 \mathrm{~A}$ and $\mathrm{B}$ shows scanning electron microscopic images of the same gold electrode before (Figure 2A) and after (Figure 2B) pretreatment with SWORC at a frequency of $8,000 \mathrm{~Hz}$ for 5 minutes. As shown in Figure 2B, the 3D-Au electrode surface was divided into two layers. The bottom layer was a brain-like nanoporous structure revealing the presence of small grains and channels about $120 \mathrm{~nm}$ in width, and the upper layer was a cotton wool-like nanostructure. The brainlike structure shown in the scanning electron microscopic images had been reported previously as being characteristic of the gold overlayers resulting from the electroreduction process. ${ }^{29}$ The atomic force microscopic images (Figure 2C and D) also revealed a difference between the surface structure of flat gold and that of 3D-Au. The surface of 3D-Au showed a rounded cap columnar-type structure composed of many grains. It should be noted that some large grains (120-150 nm) were formed by small subunits (40-60 nm). Some channels surrounded by a grain-like structure can also be observed in Figure 2D, and the width of channels was about $120 \mathrm{~nm}$.

The 3D-Au electrode was electrochemically characterized in $0.5 \mathrm{M} \mathrm{H}_{2} \mathrm{SO}_{4}$ at a scan rate of $100 \mathrm{mV}$ per seconds (Figure 2E, curve b). For comparison with the nanoporous gold electrode, the voltammogram for a bare flat gold electrode with the same geometric surface area is also presented (Figure 2E, curve a). The real surface area of the 3D-Au electrode was approximately 31 times that of the flat gold 

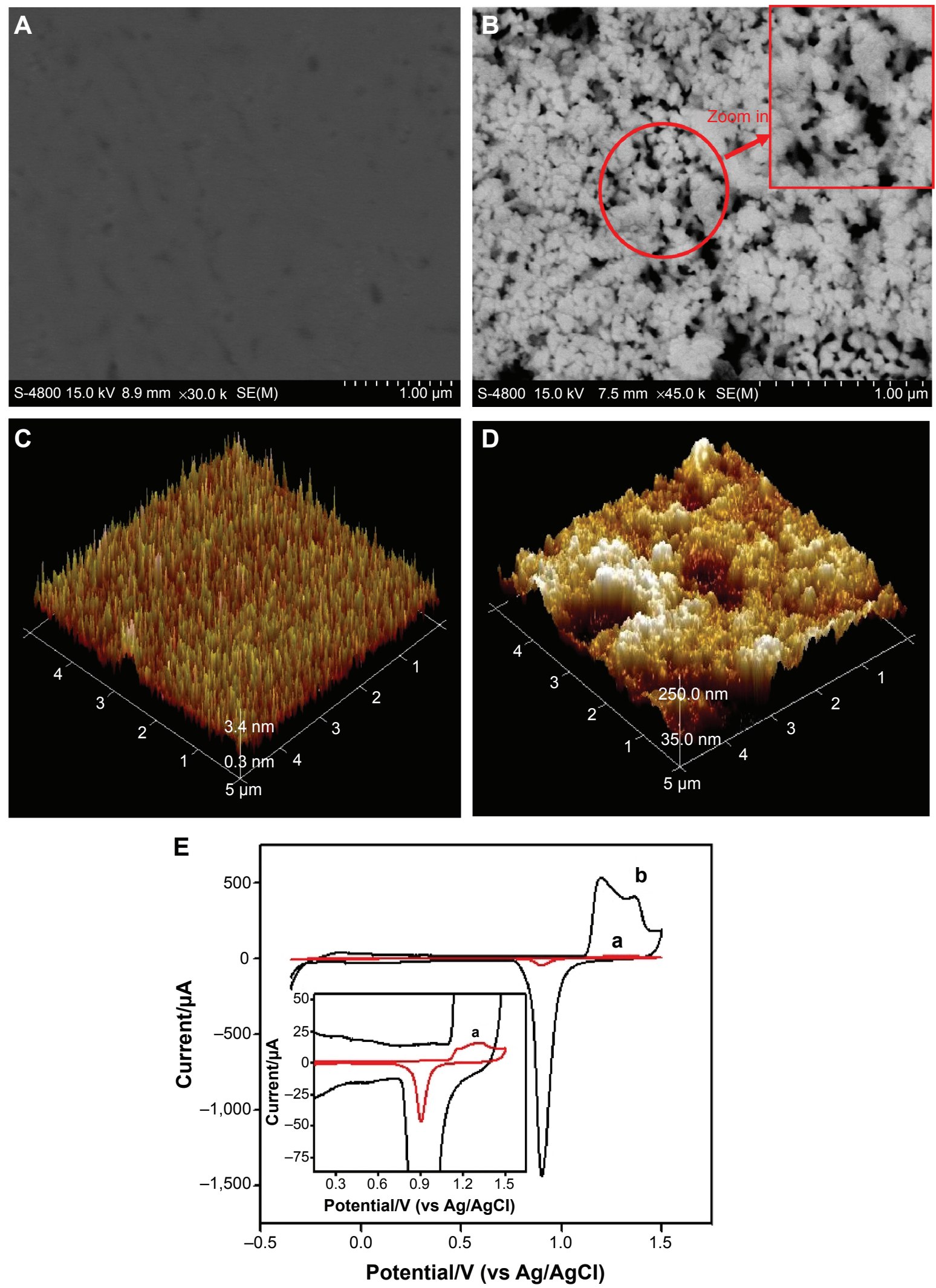

Figure 2 (A) Scanning electron microscopic images of the flat gold electrode and (B) after SWORC pretreatment. Insert is enlarged view of the image in circle. (C) ScanAsyst-mode atomic force microscopic image of flat gold electrode and (D) a 3D-Au electrode. (E) Cyclic voltammograms of a nanoporous gold electrode (curve b) and a flat gold electrode (curve a) with the same geometric area in a solution of $0.5 \mathrm{M} \mathrm{H}_{2} \mathrm{SO}_{4}$ at a scan rate of $100 \mathrm{mV}$ per second.

Abbreviations: 3D, three-dimensional; Au, gold; SWORC, square-wave oxidation-reduction cycle. 
electrode, assuming that the reduction of the monolayer of gold oxide requires $386 \mu \mathrm{C} / \mathrm{cm}^{2}$, and the roughness factor (ratio of the real surface area to the geometric surface area) is about $114 .{ }^{21}$

\section{Electrochemical responses of immunosensor based on 3D-Au electrode}

Figure 3 shows the i-t curve for the capture antibody or capture antibody/antigen/detection antibody sandwich-modified biosensor at different electrodes in TMB solution. As shown in Figure 3, curve $b$ was the i-t curve for the capture antibodymodified 3D-Au electrode after the antigen and detection antibody were immobilized on the surface of the $3 \mathrm{D}-\mathrm{Au}$ electrode by immunoreaction. The current value (curve $\mathrm{d}$ ) increased significantly, and the difference in current value between curve $d$ and curve $b$ was $3.07 \mu \mathrm{A}$. This indicates that the sandwich structure was formed upon immunoreaction, and the HRP-conjugated detection antibody was bound onto the 3D-Au electrode surface to produce the current signal. Notably, because of the site of HRP redox, which was shielded within insulating peptide backbones, the site of HRP redox did not directly exchange electrons with the electrode. ${ }^{30,31}$ Therefore, small redox molecule TMB can easily diffuse in and out of the redox site of HRP as an electron shuttle, and coupling with the redox reaction of TMB, the catalytic reduction of $\mathrm{H}_{2} \mathrm{O}_{2}$ occurs on the electrode..$^{30,31}$ Thus, the HRP modified on the surface of 3D-Au electrode could efficiently catalyze reduction reactions of $\mathrm{H}_{2} \mathrm{O}_{2}$ with the redox reaction of TMB, leading to significant amplification of current. ${ }^{31,32}$

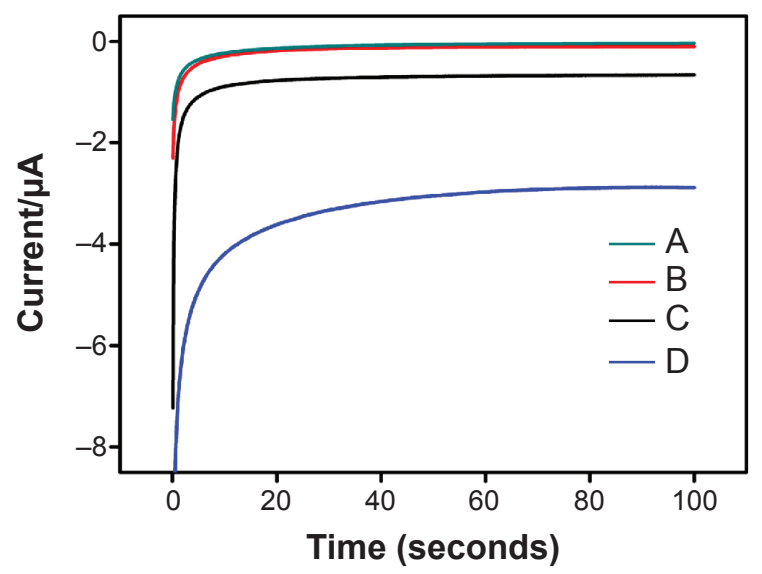

Figure 3 The i-t curves corresponding to capture antibody-modified flat gold electrode (A), capture antibody-modified 3D-Au electrode (B), capture antibody/ antigen/detection antibody sandwich-modified flat gold electrode (C), and capture antibody/antigen/detection antibody sandwich-modified 3D-Au electrode (D).

Abbreviations: 3D, three-dimensional; Au, gold.
However, due to the absence of the detection antibody, this catalytic reduction current on the capture antibody-modified 3D-Au electrode was not obvious. The phenomenon at the flat gold electrode surface (Figure 3, curves a and c) was also similar, but the current signals decreased significantly and the difference in current value between the two curves was only $0.63 \mu \mathrm{A}$. Compared with the flat gold electrode, the current difference of the 3D-Au electrode was about 4.9 times higher, demonstrating that the 3D-Au-based biosensor could significantly improve the electrocatalytic activity.

\section{Optimization of experimental conditions}

The concentration of solutions used for incubation of the capture antibody and detection antibody dramatically influenced the performance of the immunosensors. On the basis of our preliminary experiments, we set three concentrations of the solutions used for incubation of both antibodies by evaluating its effect on the blank signal. The concentration levels explored were $0.1,0.5$, and $1.0 \mathrm{mg} / \mathrm{mL}$ for the capture antibody and $0.01,0.05$, and $0.1 \mathrm{mg} / \mathrm{mL}$ for the detection antibody. As shown in Figure S1A, when the concentration of the detection antibody was fixed at $0.02 \mathrm{mg} / \mathrm{mL}$ and $0.05 \mathrm{mg} / \mathrm{mL}$, respectively, the blank signal decreased significantly with increasing concentration of the solution used for incubation of the capture antibody, whereas an opposite trend was observed for the detection antibody when concentrations of the capture antibody were fixed at $0.5 \mathrm{mg} / \mathrm{mL}$ and $1.0 \mathrm{mg} / \mathrm{mL}$, respectively. This phenomenon could be explained by the fact that a high concentration of the capture antibody solution allowed complete and regular functionalization of the nanoporous gold substrate, thus preventing nonspecific binding of detection antibody. Conversely, an excessive concentration of the solution used for incubation of the detection antibody could promote its nonspecific binding. Further experiments carried out by incubating the sensors with blank solution and with $10 \mathrm{ng} / \mathrm{mL}$ of AFP solution indicated that the signal arising from the AFP solution did not significantly decrease, even when the concentration of the detection solution was reduced to $0.02 \mathrm{mg} / \mathrm{mL}$. On the basis of these results, we fixed the concentrations of the incubating solution at 0.5 and $0.02 \mathrm{mg} / \mathrm{mL}$ for the capture and detection antibodies, respectively.

The effects of incubation temperature and incubation time on the current value for antibody and antigen reaction were also studied, as shown in Figure S1B and C, respectively. The results indicate that the optimal reaction temperature was $37^{\circ} \mathrm{C}$ and the optimal reaction time was 60 minutes. 


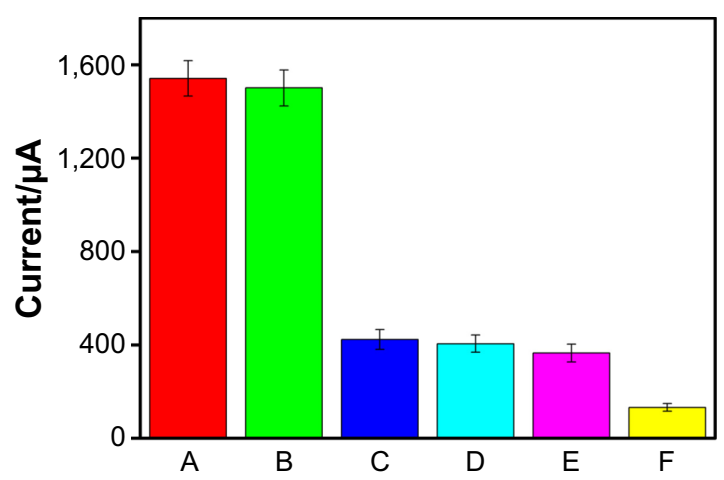

Figure 4 Amperometric response of the immunosensor to different antigens with the same concentration of $20 \mathrm{ng} / \mathrm{mL}$.

Notes: (A) $20 \mathrm{ng} / \mathrm{mL}$ AFP antigen, (B) mixed sample containing $20 \mathrm{ng} / \mathrm{mL}$ AFP antigen, $20 \mathrm{IU} / \mathrm{mL}$ CAI53 antigen, CAI99 antigen, and CAI 25 antigen, (C) $20 \mathrm{IU} /$ $\mathrm{mL} \mathrm{CAI} 53$ antigen, (D) $20 \mathrm{IU} / \mathrm{mL}$ CAI 99 antigen, (E) $20 \mathrm{IU} / \mathrm{mL} \mathrm{CAI} 25$ antigen, and (F) blank solution (not containing AFP antigen).

Abbreviation: AFP, alpha-fetoprotein.

As a result, an incubation temperature of $37^{\circ} \mathrm{C}$, a reaction time of 60 minutes, and incubating solution concentrations of $0.5 \mathrm{mg} / \mathrm{mL}$ for the capture antibody and $0.02 \mathrm{mg} / \mathrm{mL}$ for the detection antibody were selected for immunoassay of the AFP antigen.

\section{Specificity of immunosensor}

Specificity is an important parameter that influences the performance of an immunosensor in practical application. To evaluate the specificity of the presented immunosensor toward the target AFP analyte, the system was challenged with other biomarkers, including cancer antigens 153, 199, and 125. Figure 4 showed the histograms corresponding to the current intensity arising from immunoreaction of the AFP antibody with different proteins. As indicated in Figure 4, the amperometric current intensity for the target AFP increased markedly after immunoreaction with AFP antigen as compared with the other antigens and the blank solution. Meanwhile, the presence of sample matrix components did not obviously change the current intensity of the developed immunosensor toward the target AFP. The results clearly indicate the high specificity of the developed immunosensor.

\section{Sensitivity of fabricated immunosensor}

In order to examine the sensitivity of the 3D-Au-based biosensor, amperometric signals were measured before and after immunoreaction with the AFP antigen at different concentrations. Figure 5A shows an increase in the currents with increasing AFP antigen concentration in the range of 1-50 ng/mL. Under optimal conditions, a good linear relationship was observed between the current signal and the logarithmic value of the antigen concentration (shown in Figure 5B) in the range of $10-50 \mathrm{ng} / \mathrm{mL}$. The linear regression equation was $\mathrm{I}(\mu \mathrm{A})=0.9421+0.4138 \lg \mathrm{C}_{\mathrm{AFP}\left(\mathrm{ng} \mathrm{mL}^{-1}\right)}$ with a correlation coefficient 0.9950 . The lowest detection limit of $3 \mathrm{pg} / \mathrm{mL}$ AFP antigen could be estimated using $3 \sigma$ (where $\sigma$ is the standard deviation of the blank solution, $n=5$ ). According to the linear equation, the concentration of AFP antigen could be detected quantitatively, and lower serum AFP levels could also be detected by appropriate dilution with $\mathrm{pH}$ 7.4 PBS.
A

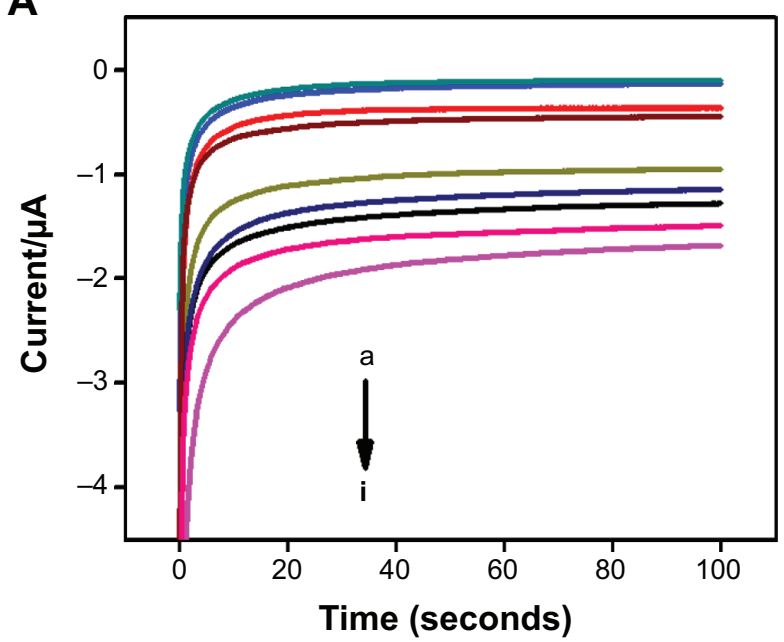

B

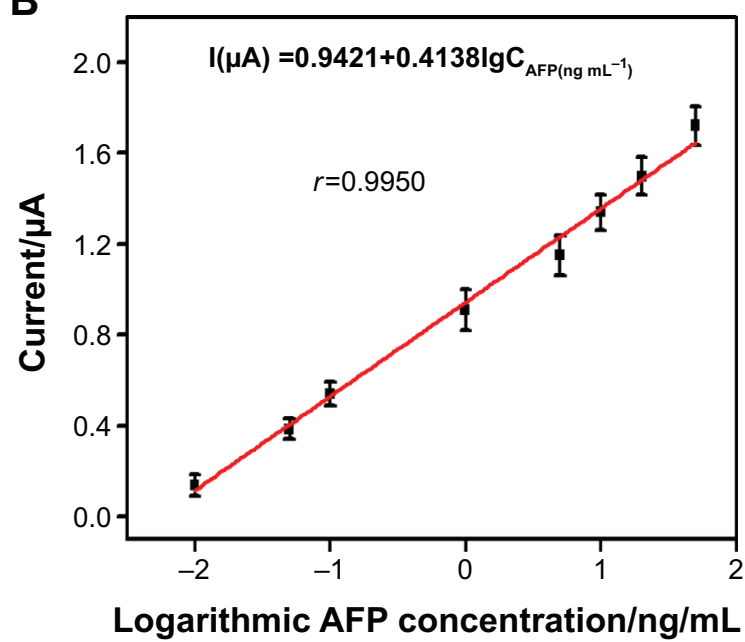

Figure 5 Current-time curves for the capture antibody-modified 3D-Au electrode before and after incubation with different concentrations of AFP antigen in TMB solution. (A) Blank solution. Curves b-i represent 0.0I, 0.05, 0.1, I.0, 5.0, 10.0, 20.0, and 50.0 ng/mL AFP antigen, respectively. (B) Linear relationship between currents and logarithmic AFP antigen concentration (from $10 \mathrm{pg} / \mathrm{mL}$ to $50 \mathrm{ng} / \mathrm{mL}$ ).

Abbreviation: AFP, alpha-fetoprotein. 
Table I Comparison of different electrochemical immunosensors

\begin{tabular}{llll}
\hline Material of modified electrode & Linear range $(\mathbf{n g} / \mathbf{m L})$ & Detection limit $(\mathbf{n g} / \mathbf{m L})$ & Reference \\
\hline $\begin{array}{l}\text { Gold nanoparticles and carbon } \\
\text { nanotubes doped with chitosan }\end{array}$ & $1.0-55.0$ & 0.6 \\
$\begin{array}{l}\text { Nanogold/toluidine blue/polysulfanilic acid } \\
\text { Silver-graphene oxide-Nafion nanocomposite }\end{array}$ & $0.5-120$ & 0.2 \\
$\begin{array}{l}\text { Gold nanoparticle/reduced graphene } \\
\text { oxide/poly (L-Arginine) }\end{array}$ & $0.01-100$ & 0.003 & 0.03 \\
$\begin{array}{l}\text { TiO(2)-graphene chitosan and gold } \\
\text { nanoparticle composite film }\end{array}$ & $0.1-300$ & 0.03 & 33 \\
$\begin{array}{l}\text { Ruthenium polypyridyl functionalized ZnO } \\
\text { mesocrystals and gold nanoparticle dotted }\end{array}$ & $0.04-500$ & 0.03 I \\
$\begin{array}{l}\text { graphene composite } \\
\text { Catalytic Au-Pd nanocrystals incorporated with }\end{array}$ & $0.05-30$ & 35 \\
highly conductive N-doped graphene sheets & $0.01-50$ & 0.005 \\
Three-dimensional nanostructured gold & & 36 \\
\hline
\end{tabular}

To further elucidate the advantage of the developed electrochemical immunosensor, the sensitivity and linear range of the immunosensor were compared with other AFP electrochemical immunosensors. ${ }^{22,33-38}$ As shown in Table 1, the sensitivity and linear range of the electrochemical immunosensor are comparable. Moreover, preparation of the 3D-Au electrode is more simple, more economical, and greener than the other nanocomposites.

\section{Precision, reproducibility, and stability of AFP immunosensor}

The precision of the electrochemical immunosensors was evaluated by calculating the intra-assay and interassay variation coefficients. The intra-assay precision of the immunosensor was evaluated by assaying one AFP level for three repeated measurements, whereas the interassay precision was estimated by measuring one AFP level with three immunosensors prepared independently under the same experimental conditions. The intra-assay and interassay variation coefficients obtained from $10 \mathrm{ng} / \mathrm{mL}$ AFP were $4.56 \%$ and $6.84 \%$, respectively, indicating acceptable precision and reproducibility. Further, the stability of the electrochemical

Table 2 Comparison of developed immunosensor and $E C L$ immunoassay analyzer in detection of serum AFP levels $(n=5)$

\begin{tabular}{llll}
\hline $\begin{array}{l}\text { Sample } \\
\text { number }\end{array}$ & $\begin{array}{l}\text { Developed } \\
\text { immunosensor } \\
(\mathbf{n g} / \mathbf{m L})\end{array}$ & RSD (\%) & $\begin{array}{l}\text { ECL immunoassay } \\
\text { analyzer }(\mathbf{n g} / \mathbf{m L})\end{array}$ \\
\hline 1 & 4.6 & 4.1 & 4.5 \\
2 & 31 & 3.8 & 32.3 \\
3 & 142 & 1.9 & 141.5 \\
\hline
\end{tabular}

Abbreviations: AFP, alpha-fetoprotein; ECL, electrochemiluminescence; RSD, relative standard deviation. immunosensor was evaluated. The immunosensors were stored at $4^{\circ} \mathrm{C}$. The amperometric currents were measured every 3-5 days using the same immunosensors. The currents were $97.3 \%, 94.9 \%$, and $91.8 \%$ of the initial current at days 10,20, and 30 . The immunosensor was regenerated by rinsing with $0.1 \mathrm{M}$ glycine- $\mathrm{HCl}(\mathrm{pH} 2.2)$ stripping buffer for 3 minutes to dissociate the antigen-antibody complex. ${ }^{39}$ The renewed immunosensor could restore $96 \%$ of the initial value after five assay runs, indicating high reusability and stability.

\section{Application of immunosensor for human AFP levels}

The AFP levels obtained in a human serum sample using the proposed immunosensor are shown in Table 2, which compares the results with those obtained from the Roche electrochemiluminescence immunoassay analyzer performed by the First Affiliated Hospital of Fujian Medical University. As shown in Table 2, the results obtained with the immunosensor are in good agreement with those measured by the electrochemiluminescence immunoassay analyzer. The relative standard deviation less than $5 \%$ in five experiments were in the acceptable range. Thus, this method has potential application for detection of AFP levels in clinical samples.

\section{Conclusion}

In this work, an electrochemical biosensor was developed based on a 3D-Au electrode, and was prepared by a simple, economical, and controllable approach known as SWORC. Due to the superior conductivity and large surface area of the 3D-Au electrode, the developed immunosensor showed excellent sensitivity and selectivity for detection of AFP antigens. Compared with other electrochemical 
immunosensors, ${ }^{22,33-38}$ the selectivity, sensitivity, and linear range of the developed immunosensor is competitive. Further, the procedure used to prepare the $3 \mathrm{D}$-Au electrode is more simple, economical, and greener than the alternative nanocomposites. This new immunosensor was also used to assay AFP levels in a human serum sample and satisfactory results were obtained. This proposed method is stable, versatile, and highly sensitive, and should have wide application in the diagnosis and monitoring of cancers or other immunoassay for non-tumor biomarkers such as immunoglobulin, glycosylated hemoglobin, and troponin.

\section{Acknowledgments}

The authors gratefully acknowledge the financial support of the National High Technology and Development of China (2012AA022604), the National Natural Science Foundation of China (21275028, 81301520), the Natural Science Foundation of Fujian Province (2014J05088), the rolling subsidy scheme of Outstanding Youth Science Fund Project of Fujian province (2014J07009), the Scientific Research Major Program of Fujian Medical University (09ZD013), the Research Fund for the Doctoral Program of Higher Education of China (20123518110001), the Fujian Provincial Important Science and Technology Foundation (2011R1007-2) sponsored by the Medical Elite Cultivation Program of Fujian, People's Republic of China (2013-ZQN-JC-5), the Science and Technology Plan Project, General Administration of Quality Supervision (2014IK060), the Foundation of Fujian Provincial Department of Education (JA11110, JA12130), and the Key Clinical Specialty Discipline Construction Program of Fujian, People's Republic of China.

\section{Disclosure}

The authors report no conflicts of interest in this work.

\section{References}

1. Liu G, Wang S, Liu J, Song D. An electrochemical immunosensor based on chemical assembly of vertically aligned carbon nanotubes on carbon substrates for direct detection of the pesticide endosulfan in environmental water. Anal Chem. 2012;84(9):3921-3928.

2. Liu J, Zanardi S, Powers S, Suman M. Development and practical application in the cereal food industry of a rapid and quantitative lateral flow immunoassay for deoxynivalenol. Food Control. 2012;26(1): $88-91$.

3. Al-Khafaji QAM, Harris M, Tombelli S, et al. An electrochemical immunoassay for HER2 detection. Electroanalysis. 2012;24(4):735-742.

4. Uludag Y, Tothill IE. Cancer biomarker detection in serum samples using surface plasmon resonance and quartz crystal microbalance sensors with nanoparticle signal amplification. Anal Chem. 2012; 84(14):5898-5904.
5. Kim YJ, Rahman MM, Lee JJ. Ultrasensitive and label-free detection of annexin A3 based on quartz crystal microbalance. Sens Actuators B Chem. 2013;177:172-177.

6. Wenger B, Kugelbrey K, Gao H, Sigrist H, Voirin G. Au-labeled antibodies to enhance the sensitivity of a refractometric immunoassay: detection of cocaine. Biosens Bioelectron. 2012;34(1):94-99.

7. Zhang Y, Dai WJ, Liu F, et al. Ultrasensitive electrochemiluminescent immunosensor based on dual signal amplification strategy of gold nanoparticles-dotted graphene composites and CdTe quantum dots coated silica nanoparticles. Anal Bioanal Chem. 2013;405(14):4921-4929.

8. Liu L, Xing Y, Zhang H, Liu R, Liu H, Xia N. Amplified voltammetric detection of glycoproteins using 4-mercaptophenylboronic acid/biotin-modified multifunctional gold nanoparticles as labels. Int J Nanomedicine. 2014;9(1):2619-2626.

9. Dempsey E, Diamond D, Collier A. Development of a biosensor for endocrine disrupting compounds based on tyrosinase entrapped within a poly(thionine) film. Biosens Bioelectron. 2004;20(2):367-377.

10. Hahm J, Lieber CM. Direct ultrasensitive electrical detection of DNA and DNA sequence variations using nanowire nanosensors. Nano Lett. 2004;4(1):51-54.

11. Sánchez S, Pumera M, Fàbregas E. Carbon nanotube/polysulfone screen-printed electrochemical immunosensor. Biosens Bioelectron. 2007;23(3):332-340.

12. Rahman MA, Son JI, Won MS, Shim YB. Gold nanoparticles doped conducting polymer nanorod electrodes: ferrocene catalyzed aptamer-based thrombin immunosensor. Anal Chem. 2009;81(16): 6604-6611.

13. Bangar MA, Shirale DJ, Chen W, Myung NV, Mulchandani A. Single conducting polymer nanowire chemiresistive label-free immunosensor for cancer biomarker. Anal Chem. 2009;81(6):2168-2175.

14. Li F, Han XP, Liu SF. Development of an electrochemical DNA biosensor with a high sensitivity of $\mathrm{fM}$ by dendritic gold nanostructure modified electrode. Biosens Bioelectron. 2011;26(5):2619-2625.

15. Deng YP, Huang W, Chen X, Li ZL. Facile fabrication of nanoporous gold film electrodes. Electrochem Commun. 2008;10(5):810-813.

16. Zhang HF, Hussain I, Brust M, Butler MF, Rannard SP, Cooper AI. Aligned two- and three-dimensional structures by directional freezing of polymers and nanoparticles. Nat Mater. 2005;4(10):787-793.

17. Weissmüller J, Viswanath RN, Kramer D, Zimmer P, Würschum R, Gleiter H. Charge-induced reversible strain in a metal. Science. 2003; 300(5617):312-315.

18. Zielasek V, Jürgens B, Schulz C, et al. Gold catalysts: nanoporous gold foams. Angew Chem Int Ed. 2006;45(48):8241-8244.

19. Lang XY, Guo H, Chen LY, et al. Novel nanoporous Au-Pd alloy with high catalytic activity and excellent electrochemical stability. J Phys Chem C. 2010;114(6):2600-2603.

20. Hu KC, Lan DX, Li XM, Zhang S. Electrochemical DNA biosensor based on nanoporous gold electrode and multifunctional encoded DNA-Au bio bar codes. Anal Chem. 2008;80(23):9124-9130.

21. Gao W, Xia XH, Xu JJ, Chen HY. Three-dimensionally ordered macroporous gold structure as an efficient matrix for solid-state electrochemiluminescence of Ru(bpy)32+/TPA system with high sensitivity. J Phys Chem C. 2007;111(13):12213-12219.

22. Li Y, Song YY, Yang C, Xia XH. Hydrogen bubble dynamic template synthesis of porous gold for nonenzymatic electrochemical detection of glucose. Electrochem Commun. 2007;9(5):981-988.

23. Gamero M, Pariente F, Lorenzo E, Alonso C. Nanostructured rough gold electrodes for the development of lactate oxidase-based biosensors. Biosens Bioelectron. 2010;25(9):2038-2044.

24. Zhong GX, Liu AL, Chen XH, et al. Electrochemical biosensor based on nanoporous gold electrode for detection of PML/RAR $\alpha$ fusion gene. Biosens Bioelectron. 2011;26(9):3812-3817.

25. Zhong GX, Liu AL, Xu XW, et al. Detection of femtomolar level osteosarcoma-related gene via a chronocoulometric DNA biosensor based on nanostructure gold electrode. Int J Nanomedicine. 2012;7: 527-536. 
26. Shim JH, Yoon DL, Han S, et al. Is serum alpha-fetoprotein useful for predicting recurrence and mortality specific to hepatocellular carcinoma after hepatectomy? A test based on propensity scores and competing risks analysis. Ann Surg Oncol. 2012;19(12):3687-3696.

27. Ho HK, Pok S, Streit S, et al. Fibroblast growth factor receptor 4 regulates proliferation, anti-apoptosis and alpha-fetoprotein secretion during hepatocellular carcinoma progression and represents a potential target for therapeutic intervention. J Hepatol. 2009;50(1):118-127.

28. Fan $\mathrm{CH}$, Plaxco KW, Heeger AJ. Electrochemical interrogation of conformational changes as a reagentless method for the sequencespecific detection of DNA. Proc Nat Acad Sci U S A. 2003;100(16): 9134-9137.

29. Vazquez L, Bartolome A, Baro AM. STM-SEM combination study on the electrochemical growth mechanism and structure of gold overlayers: a quantitative approach to electrochemical metal surface roughening. Surf Sci. 1989;215(1-2):171-189.

30. Liu G, Wan Y, Gau V, et al. An enzyme-based e-DNA sensor for sequence-specific detection of femtomolar DNA targets. J Am Chem Soc. 2008;130(21):6820-6825.

31. Fanjul-Bolado P, Gonzalez-Garcia MB, Costa-Garcia A. Amperometric detection in TMB/HRP-based assays. Anal Bioanal Chem. 2005; 382(2):297-302.

32. Das A, Hecht MH. Peroxidase activity of de novo heme proteins immobilized on electrodes. J Inorg Biochem. 2007;101(11-12):1820-1826.
33. Yang S, Jia WZ, Qian QY, Zhou YG, Xia XH. Simple approach for efficient encapsulation of enzyme in silica matrix with retained bioactivity. Anal Chem. 2009;81(9):3478-3484.

34. Wu YM, Xu WJ, Wang Y, Yuan YL, Yuan R. Silver-graphene oxide nanocomposites as redox probes for electrochemical determination of o-1-fetoprotein. Electrochim Acta. 2013;88:135-140.

35. Park JY, Lee YS, Kim BH, Park SM. Label-free detection of antibodyantigen interactions on (R)-lipo-diaza-18-crown-6 self-assembled monolayer modified gold electrodes. Anal Chem. 2008;80(13):4986-4993.

36. Huang KJ, Li J, Wu YY, Liu YM. Amperometric immunobiosensor for $\alpha$-fetoprotein using $\mathrm{Au}$ nanoparticles/chitosan/TiO(2)-graphene composite based platform. Bioelectrochemistry. 2013;90:18-23.

37. Liu S, Zhang J, Tu W, Bao J, Dai Z. Using ruthenium polypyridyl functionalized $\mathrm{ZnO}$ mesocrystals and gold nanoparticle dotted graphene composite for biological recognition and electrochemiluminescence biosensing. Nanoscale. 2014;6(4):2419-2425.

38. Zhao L, Li S, He J, Tian G, Wei Q, Li H. Enzyme-free electrochemical immunosensor configured with Au-Pd nanocrystals and N-doped graphene sheets for sensitive detection of AFP. Biosens Bioelectron. 2013;49:222-225.

39. Lin J, Wei Z, Zhang H, Shao M. Sensitive immunosensor for the label-free determination of tumor marker based on carbon nanotubes/ mesoporous silica and graphene modified electrode. Biosens Bioelectron. 2013;41:342-347. 


\section{Supplementary material}

A Detection antibody concentration $(\mathrm{mg} / \mathrm{mL})$

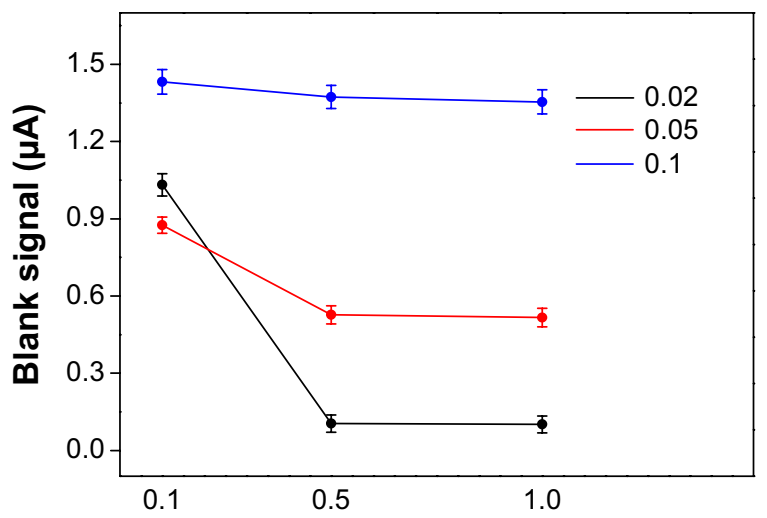

Capture antibody concentration $(\mathrm{mg} / \mathrm{mL})$

B

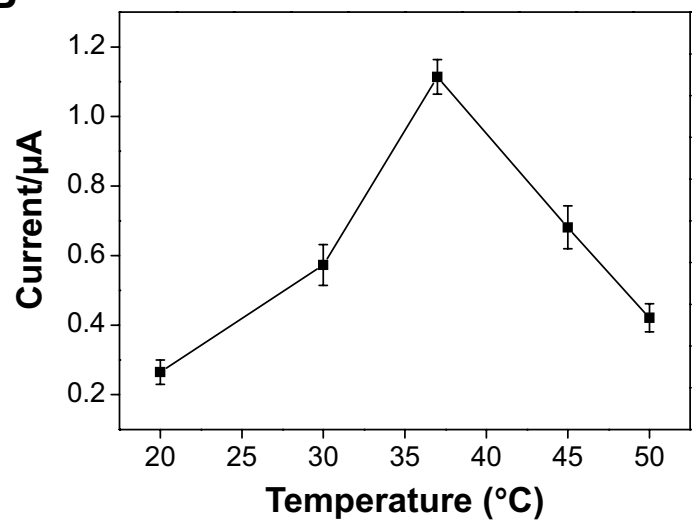

C

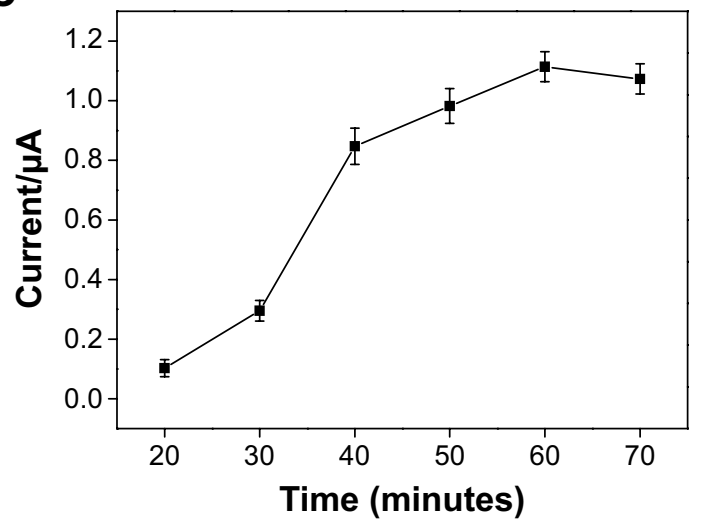

Figure SI (A) Effect of the concentration of the solutions used on incubation of capture and detection antibodies on the blank signal acquired after incubation with AFP-free solution. (B) Effect of incubation temperature on antigen-antibody interaction. (C) Effect of antigen-antibody incubation time on response of amperometric current.

\section{Publish your work in this journal}

The International Journal of Nanomedicine is an international, peerreviewed journal focusing on the application of nanotechnology in diagnostics, therapeutics, and drug delivery systems throughout the biomedical field. This journal is indexed on PubMed Central, MedLine, CAS, SciSearch $®$, Current Contents ${ }^{\circledR} /$ Clinical Medicine,
Journal Citation Reports/Science Edition, EMBase, Scopus and the Elsevier Bibliographic databases. The manuscript management system is completely online and includes a very quick and fair peer-review system, which is all easy to use. Visit http://www.dovepress.com/ testimonials.php to read real quotes from published authors. 